\title{
Enhancing the Step Response of Hybrid Stepper Motors
}

\author{
\{A.A. Sarhan, R.H. Hafez, A. El-Wakeel and U. AbouZayed ${ }^{*}$
}

\begin{abstract}
In this paper, the basic differential equations of hybrid stepper motor are used to build up a model using MATLAB software package. The implementation of fuzzy logic (FL) and proportional-integral-derivative (PID) controllers are used to improve the step response of the hybrid stepper motor. The numerical simulations by a PC-based controller show that the PID controller tuned by genetic algorithm produces better performance than tuned by fuzzy controller. Fuzzy PID-like controller gives better performance than the other linear fuzzy controllers. Finally, the comparison between PID controllers tuned by genetic algorithm and fuzzy PID-like controller shows that, the fuzzy PID-like controller produce better performance.
\end{abstract}

Keywords: Hybrid stepper motor, fuzzy controller, PID controller, genetic algorithm.

\section{Introduction}

Stepper motors are a type of electromagnetic mechanical devices which can convert discrete electric impulses into angular displacement or linear displacement. Their output angular displacement is directly proportional to the amount of the input pulses, and their speed of rotation is directly proportional to the frequency of the input pulses [1]. These motors possess all the advantages of standard permanent magnet (PM) synchronous machines while their cost is much lower [2]. Stepping motors are the ideal choice for those applications where power is small (less than 100 watt) while position control must be sharp and fast, such as in robotics, aerospace applications, machine tools, printers, scanners, and servos [3].

Stepper motors have several merits such as great output torque, small inertia, and high frequency response. These features contribute to the wide usage in the industry nowadays, especially in measurement and control applications [1]. Stepper motors have also some demerits such as step response with overshoot and relatively long settling time. Besides, loss of synchronism appears when steps of high frequency are given. It is thus necessary to develop control schemes to improve the performance of stepper motors [4].

Recently, the positioning systems are being implemented using stepper motors instead of traditionally DC motors [5]. This is because, for high speed repetitive motion, the brushes in DC motors are subject to excessive mechanical wear and consequently lead to a decrease in performance. Also, since there is a winding on the rotor of DC motors, the rotor copper loss and hence the heat does not have a direct path to the outside environment, but instead must be dissipated through the stator. Another important aerospace application of the stepper motors is that, in order to achieve uniform performance throughout the life span of more than 10 years and to avoid unpredictable and intolerable disturbances to the satellite, the stepper motors are required to deliver a constant torque $[6,7]$.

\footnotetext{
* Egyptian Armed Forces, Egypt.
} 


\section{Mathematical Model for Hybrid Stepper Motor}

Basically, the model of the hybrid stepper motors can be expressed in forms of equations as follows $[4,8,9]$ :

$L \frac{d i_{a}}{d t}=-R i_{a}+K_{c} \omega \sin \left(N_{r} \theta\right)+v_{a}$

$L \frac{d i_{b}}{d t}=-R i_{b}+K_{c} \omega \cos \left(N_{r} \theta\right)+v_{b}$

$J \frac{d \omega}{d t}=-i_{a} K_{c} \sin \left(N_{r} \theta\right)+i_{b} K_{c} \cos \left(N_{r} \theta\right)-\tau_{L}$

$\omega=\frac{d \theta}{d t}$

where $v_{a}$ and $i_{a}$ are the voltage and current in phase $(a)$ respectively, $v_{b}$ and $i_{b}$ are the voltage and current in phase $(b)$ respectively, $\omega$ is the rotor angular speed, $\theta$ is rotor position angle, $R$ and $L$ are the phase winding resistance and inductance respectively, $B$ is the friction coefficient, $J$ is the rotor inertia, $K_{c}$ is the motor torque constant, $\tau_{L}$ is the load torque, and $N_{r}$ is the number of rotor teeth.

In this paper, MATLAB software is used to solve, simulate, study and investigate the motor performance subject to different conditions. The motor model is shown in figure (1).



Fig. 1 Hybrid stepper motor model using MATLAB toolbox

\section{Fuzzy Logic Controller (FLC)}

The FLC provides an algorithm, which converts the linguistics control based on expert knowledge into an automatic control strategy. Therefore, the FLC algorithm is much closer in spirit to human thinking than traditional logical systems [10]. FLC provides a formal methodology for representing, manipulating, and implementing a human's heuristic 
knowledge about how to control a system [11]. The block diagram in figure (2) shows a fuzzy control embedded in a closed-loop control system. The plant output is denoted by $y(t)$, its input is denoted by $u(t)$, and the reference input to the fuzzy controller is denoted by $r(t)$. As shown in figure (2), the fuzzy control has four main components: the rule-base, the inference mechanism, the fuzzification interface, and the de-fuzzification interface.

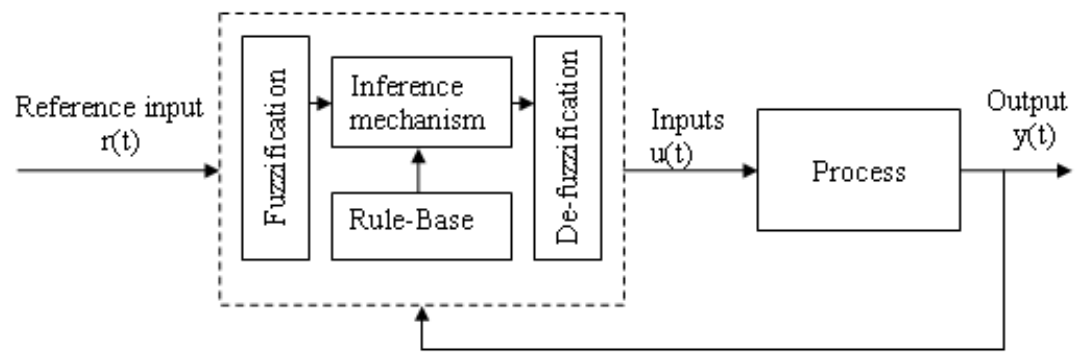

Fig. 2 Fuzzy controller architecture

The "rule-base" holds the knowledge, in the form of a set of rules (if-then rules), of how best to control the system [12]. The inference mechanism evaluates which control rules are relevant at the current time and then decides what the input to the plant should be. The fuzzification interface simply modifies the inputs so that they can be interpreted and compared to the rules in the rule-base. The de-fuzzification interface converts the conclusions reached by the inference mechanism into inputs to the plant [13]. There are several types of linear FLC [12]: Fuzzy Proportional (FP), Fuzzy Proportional-Derivative (FPD), Fuzzy Proportional-Derivative-plus-Integral (FPD+I), Fuzzy Incremental (FI), and Fuzzy PID-like controller.

The FP controller is derived from the PID controller with the I-action set to zero $\left(\frac{1}{T_{i}}=0\right)$ and the D-action set to zero $\left(T_{d}=0\right)$ where, $T_{i}$ and $T_{d}$ are the integral and derivative time constants, respectively. As shown in figure (3), FP controller acts on the error $(e)$, and its control signal is $(U)$. The FP controller has two tuning gains: error gain $(G E)$ and output gain $(G U)$, where the crisp proportional controller has just one, $K_{P}$. The control signal $U(n)$, at the time instant $(n)$ is generally a nonlinear function of the input $e(n)$.

$U(n)=f(G E \cdot e(n)) \cdot G U$

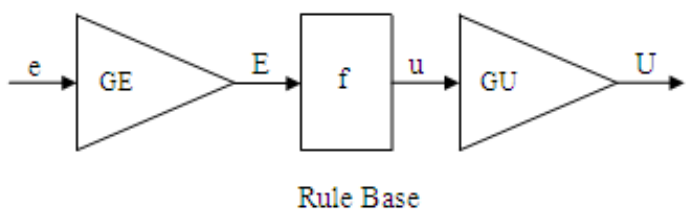

Fig. 3 FP Controller

The FPD type control generates control output from error and change of error as shown in figure (4). Derivative action helps to predict the future error, and the PD controller uses the derivative action to improve closed-loop stability. 




Fig. 4 FPD Controller

The control signal $U(n)$, at the time instant $(n)$, is a nonlinear function of error and change in error is:

$U(n)=f(G E . e(n), G C E . \dot{e}(n)) \cdot G U$

where $G C E$ is the change of error gain.

If the closed-loop system exhibits a sustained error in steady state, integral action is necessary. The integral action will increase (or decrease) the control signal if there is a positive (or negative) error, even for small magnitudes of the error. Thus, a controller with integral action will always return to the reference in steady state. A fuzzy PID controller acts on three inputs: error, integral error, and change in error. A rule base with three premise inputs can be a problem. To overcome this problem, a simple design is to combine crisp integral action and a fuzzy PD rule base in the fuzzy PD+I (FPD+I) controller as in figure (5).

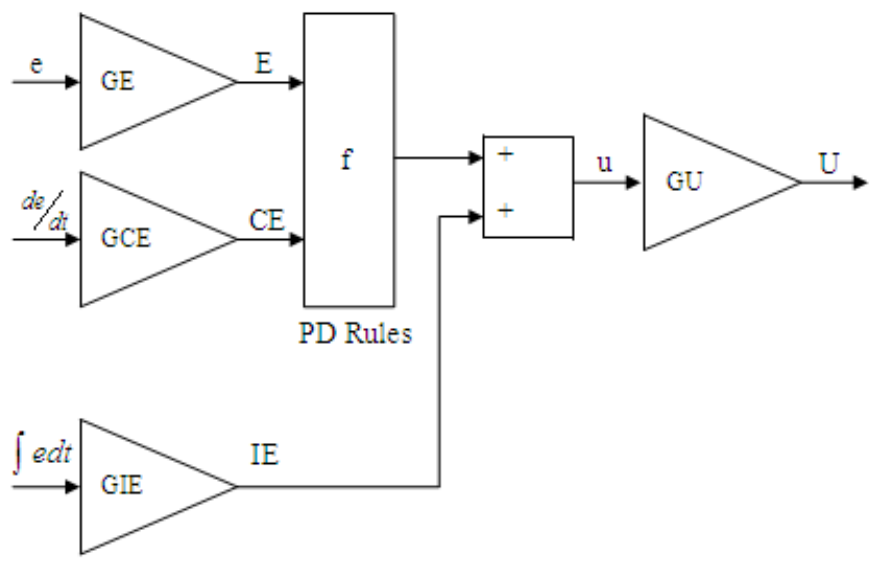

Fig. 5 FPD+I Controller

The control signal $U(n)$ at the time instant $(n)$, is a nonlinear function of error, change in error, and integral error as:

$U(n)=\left[f(G E . e(n), G C E . \dot{e}(n))+G I E \sum_{j=1}^{n} e(j) T_{s}\right] \cdot G U$

where $T_{s}$ is the sampling time and GIE is the integral error gain. 
The fuzzy incremental controller in figure (6) is of almost the same configuration as the FPD controller except for the added integrator. The conclusion in the rule base is now called change in output $(c u)$, and the gain on the output is, accordingly, GCU.

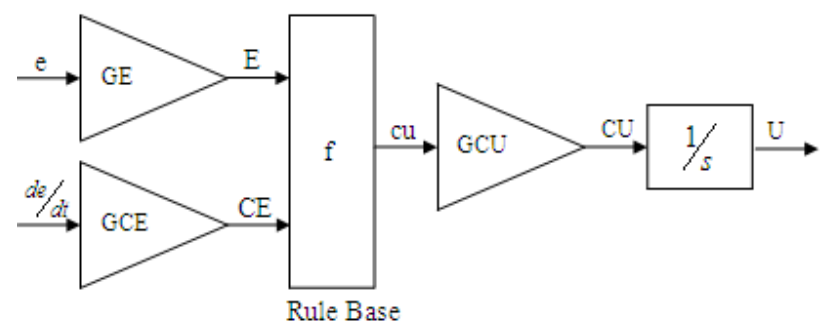

Fig. 6 Fuzzy Incremental Controller

The control signal $U(n)$ at time instant $(n)$ is the sum of all previous increments and can be expressed as:

$$
\begin{aligned}
U(n) & =\sum_{j=1}^{n}\left(c u(j) \cdot G C U \cdot T_{s}\right) \\
& =\sum_{j=1}^{n}\left(f(G E \cdot e(j), G C E \cdot \dot{e}(j)) \cdot G C U \cdot T_{s}\right)
\end{aligned}
$$

A Fuzzy PID-like controller is a fuzzified PID controller. It acts on the same input signals, but the control strategy is formulated as Fuzzy rules. A Fuzzy PID-like controller structure is simply formed by connecting the FPD type and FIC together in parallel as shown in figure (7).

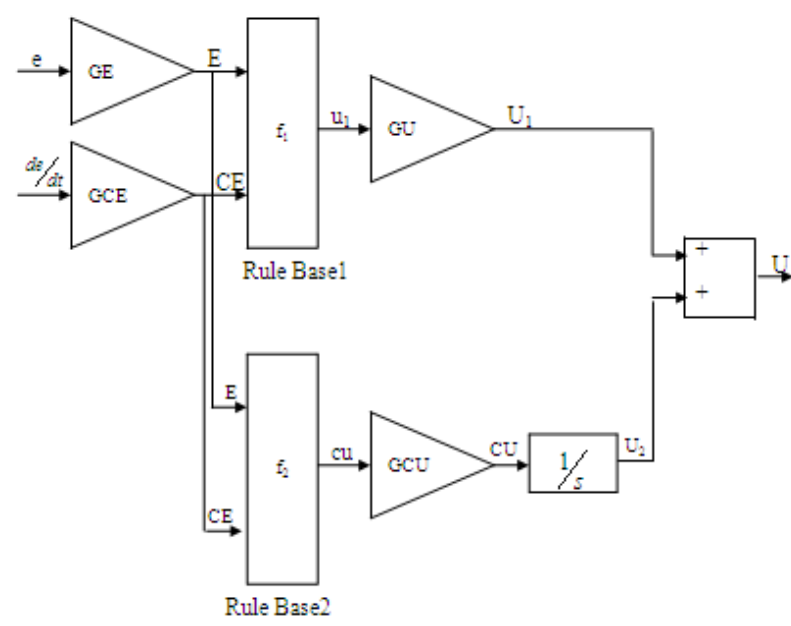

Fig. 7 Fuzzy PID-like controller Fuzzy

The control signal $U(n)$, at the time instant $(n)$, is the sum of $U_{1}$ and $U_{2}$.

$$
\begin{aligned}
U(n)= & U_{1}+U_{2} \\
= & f_{1}(G E \cdot e(n), G C E \cdot \dot{e}(n)) \cdot G U+ \\
& \sum\left(f_{2}(G E \cdot e(j), G C E \cdot \dot{e}(j)) \cdot G C U \cdot T_{s}\right)
\end{aligned}
$$




\section{Genetic Algorithm (GA)}

GA is simple, powerful, general-purpose, derivative-free, stochastic global optimization methods inspired by the laws of natural selection and genetics. These algorithms are derivative-free, which means that they do not need functional derivative information to search for a set of parameters that minimize (or maximize) a given objective function. Instead, they exclusively rely on repeated evaluations of the objective function, and the subsequent search direction after each evaluation follows certain heuristic guidelines. In particular, the optimum solution is obtained by investigating new solutions which incorporate three genetic operations: reproduction, crossover, and mutation in a selective environment where the fittest survive [14]. There are three main steps for genetic algorithm, random initialization of population, evaluation of fitness function and finally generation of new population.

In random initialization of population, the initial population is created randomly with even number $(N)$ of individuals. An individual is characterized by a fixed-length binary bit string, which is called a chromosome. In evaluation of fitness function all the individuals of the initially created population are evaluated by means of a fitness function $(f)$. The fitness function is then used in the next step, to create a genetic pool. After evaluating the fitness of the individuals of the initial population, a new population is created. The creation of a new generation is performed basically in three stages, reproduction, crossover and mutation. The overall goal of this step is to obtain a new population with individuals which have high fitness values.

In reproduction stage, the individuals are selected among the population with probabilities proportional to their fitness values. In this way, individuals with lower fitness values are eliminated whilst others are copied to the next generation one or more times, and some are not copied at all. The population after reproduction stage is called mating pool.

In crossover stage, a genetic crossover operator is applied to the mating pool to generate new individuals. Thus individuals of the mating pool are paired randomly, and $\frac{N}{2}$ genetic couples are obtained. There are many crossover operators can be used but the most basic crossover operator is the one-point crossover operator, in this case a crossover point in the string bits of the selected pair is randomly chosen, and the bits of the two parents are interchanged at this point as shown in figure (8). In two-point crossover operation, the two crossover points are selected in the binary strings of the pair under consideration and between these points the bits are swapped as shown in figure (9). This crossover process is similar to the mating process in a biological system, where parents pass segments of chromosomes to their offspring and thus offspring can outperform their parents if they get 'good' genes from both parents.



Fig. 8 One-point crossover

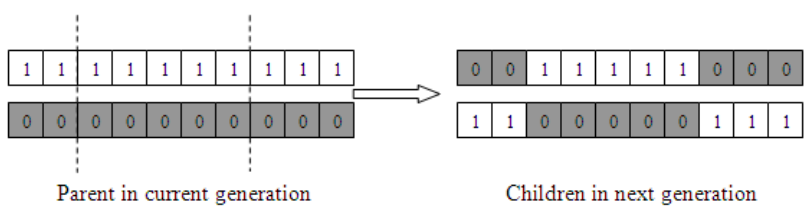

Fig. 9 Two-point crossover 
The crossover process is followed by a mutation process, which introduces further changes to a bit string. This is required, since if the population does not contain all the encoded information required to solve a specific problem, no amount of gene mixing can provide a satisfactory solution. By applying the mutation operator, it is possible to produce new chromosomes. This can be implemented in various ways, and the most common technique is to change a randomly chosen bit in the bit string of the individual to be mutated. Thus certain bit is changed from 1 into 0 or from 0 into 1 . Finally, it can be said that the crossover and mutation together give genetic algorithms most of their searching power [15].

\section{Simulation Results}

The hybrid stepper motor with data given in table (1) is used in the simulation. While control rules for FLC are shown in table (2). Tables (3), (4), and (5) show the control rules for selftuning of the PID controller.

Table 1 Hybrid stepper motor parameters.

\begin{tabular}{l|l}
\hline \hline Motor phase resistance $(\Omega)$ & $\mathrm{R}=10$ \\
\hline Motor phase inductance $(\mathrm{H})$ & $\mathrm{L}=0.001$ \\
\hline Machine torque constant $(\mathrm{Nm} / \mathrm{A})$ & $\mathrm{K}_{\mathrm{C}}=0.113$ \\
\hline Applied DC phase voltage $(\mathrm{V})$ & $\mathrm{V}_{\mathrm{s}}=5$ \\
\hline Friction coefficient $\quad(\mathrm{Nm} . \mathrm{s} / \mathrm{rad})$ & $\mathrm{B}=0.00$ \\
\hline Inertia constant $\quad\left(\mathrm{kg} . \mathrm{m}^{2}\right)$ & $\mathrm{J}=0.00005$ \\
\hline Number of rotor teeth & $\mathrm{N}_{\mathrm{r}}=50$ \\
\hline \hline
\end{tabular}

Table 2 Control Rules of FLC

\begin{tabular}{c||c|c|c|c|c|c|c}
\hline$\dot{e} / e$ & NB & NM & NS & ZR & PS & PM & PB \\
\hline \hline NB & NB & NB & NB & NB & NM & NS & ZR \\
\hline NM & NB & NB & NB & NM & NS & ZR & PS \\
\hline NS & NB & NB & NM & NS & ZR & PS & PM \\
\hline ZR & NB & NM & NS & ZR & PS & PM & PB \\
\hline PS & NM & NS & ZR & PS & PM & PB & PB \\
\hline PM & NS & ZR & PS & PM & PB & PB & PB \\
\hline PB & ZR & PS & PM & PB & PB & PB & VB \\
\hline \hline
\end{tabular}

Table 4 Rule base for determining the gain $K_{i}$

\begin{tabular}{c||c|c|c|c|c}
\hline \hline$\dot{e} / e$ & $\mathrm{NB}$ & $\mathrm{NS}$ & $\mathrm{ZE}$ & $\mathrm{PS}$ & $\mathrm{PB}$ \\
\hline \hline $\mathrm{NB}$ & $\mathrm{M}$ & $\mathrm{M}$ & $\mathrm{M}$ & $\mathrm{M}$ & $\mathrm{M}$ \\
\hline $\mathrm{NS}$ & $\mathrm{S}$ & $\mathrm{S}$ & $\mathrm{S}$ & $\mathrm{S}$ & $\mathrm{S}$ \\
\hline ZE & $\mathrm{MS}$ & $\mathrm{MS}$ & $\mathrm{ZE}$ & $\mathrm{MS}$ & $\mathrm{MS}$ \\
\hline $\mathrm{PS}$ & $\mathrm{S}$ & $\mathrm{S}$ & $\mathrm{S}$ & $\mathrm{S}$ & $\mathrm{S}$ \\
\hline $\mathrm{PB}$ & $\mathrm{M}$ & $\mathrm{M}$ & $\mathrm{M}$ & $\mathrm{M}$ & $\mathrm{M}$ \\
\hline \hline
\end{tabular}

Table 3 Rule base for determining the gain $K_{P}$.

\begin{tabular}{c|c|c|c|c|c}
\hline \hline$\dot{e} / e$ & $\mathrm{NB}$ & $\mathrm{NS}$ & $\mathrm{ZE}$ & $\mathrm{PS}$ & $\mathrm{PB}$ \\
\hline \hline $\mathrm{NB}$ & $\mathrm{VB}$ & $\mathrm{VB}$ & $\mathrm{VB}$ & $\mathrm{VB}$ & $\mathrm{VB}$ \\
\hline $\mathrm{NS}$ & $\mathrm{B}$ & $\mathrm{B}$ & $\mathrm{B}$ & $\mathrm{MB}$ & $\mathrm{VB}$ \\
\hline $\mathrm{ZE}$ & $\mathrm{ZE}$ & $\mathrm{ZE}$ & $\mathrm{MS}$ & $\mathrm{S}$ & $\mathrm{S}$ \\
\hline $\mathrm{PS}$ & $\mathrm{B}$ & $\mathrm{B}$ & $\mathrm{B}$ & $\mathrm{MB}$ & $\mathrm{VB}$ \\
\hline $\mathrm{PB}$ & $\mathrm{VB}$ & $\mathrm{VB}$ & $\mathrm{VB}$ & $\mathrm{VB}$ & $\mathrm{VB}$ \\
\hline \hline
\end{tabular}

Table 5 Rule base for determining the gain $K_{d}$

\begin{tabular}{c|c|c|c|c|c}
\hline \hline$\dot{e} / e$ & $\mathrm{NB}$ & $\mathrm{NS}$ & $\mathrm{ZE}$ & $\mathrm{PS}$ & $\mathrm{PB}$ \\
\hline \hline $\mathrm{NB}$ & $\mathrm{ZE}$ & $\mathrm{S}$ & $\mathrm{M}$ & $\mathrm{MB}$ & $\mathrm{VB}$ \\
\hline $\mathrm{NS}$ & $\mathrm{S}$ & $\mathrm{B}$ & $\mathrm{MB}$ & $\mathrm{VB}$ & $\mathrm{VB}$ \\
\hline $\mathrm{ZE}$ & $\mathrm{M}$ & $\mathrm{MB}$ & $\mathrm{MB}$ & $\mathrm{VB}$ & $\mathrm{VB}$ \\
\hline $\mathrm{PS}$ & $\mathrm{B}$ & $\mathrm{VB}$ & $\mathrm{VB}$ & $\mathrm{VB}$ & $\mathrm{VB}$ \\
\hline $\mathrm{PB}$ & $\mathrm{VB}$ & $\mathrm{VB}$ & $\mathrm{VB}$ & $\mathrm{VB}$ & $\mathrm{VB}$ \\
\hline \hline
\end{tabular}


First of all, the model is verified by comparing its response with the built-in hybrid stepper motor model obtained in MATLAB Simulink toolbox. The comparison results are shown in figure (10). It is clear from the comparison that the error in the rotor position, motor speed, or electromagnetic torque is too small and can be neglected.

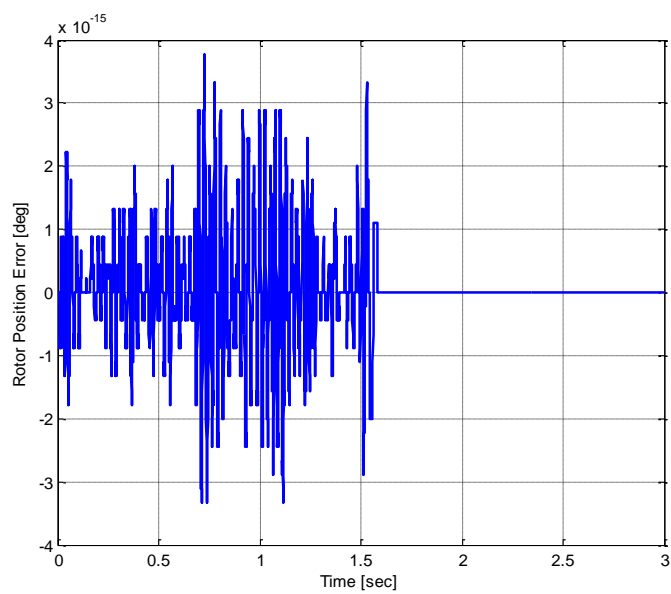

(a) Rotor position error

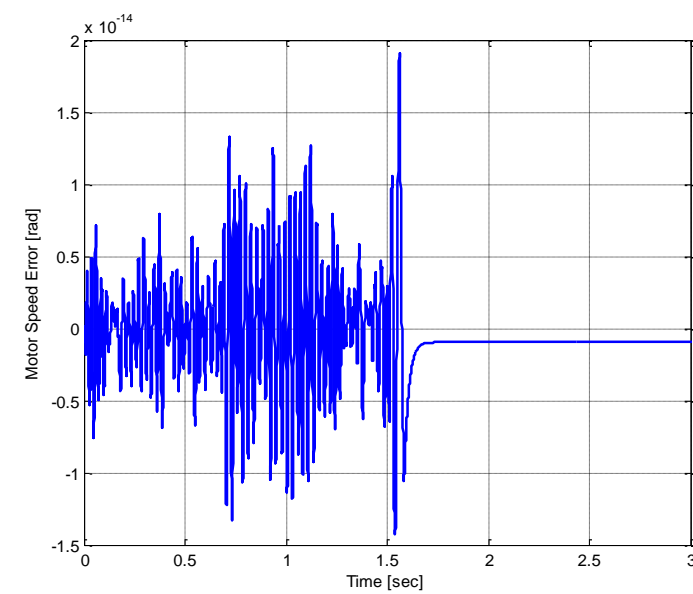

(b) Motor speed error

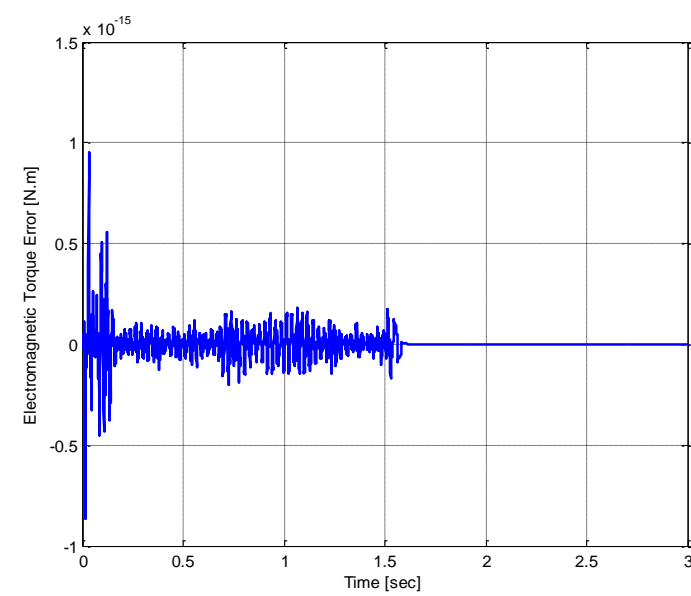

(c) Electromagnetic torque error

\section{Fig. 10 Results for new model verification}

The hybrid stepper motor is investigated on open loop control. This investigation includes the study of the motor position, rotor speed, and electromagnetic generated torque on the shaft as shown in figure (11).

The motor performance using PID controller with different tuning methods is compared. The tuning of the PID controller by GA is carried out using a MATLAB built-in routine so called Simulink Response Optimization (SRO) Toolbox. The SRO, automatically, formulates an optimization problem and calls a GA and direct search toolbox, as an optimization routine to solve the problem [11]. It is clear from figure (12) that, PID controller with GA provides better performance. The three types of PID controller have no overshoot and co steady state error. PID controller with GA has the lowest rise time and settling time. 


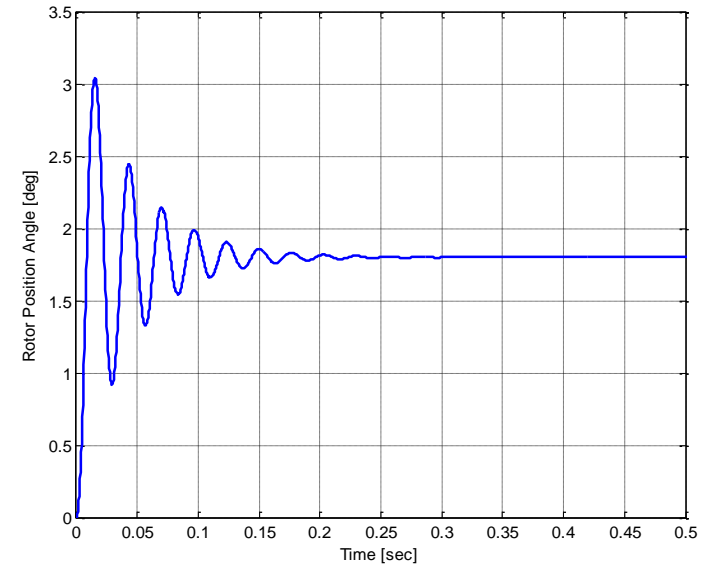

(a) Rotor position angle

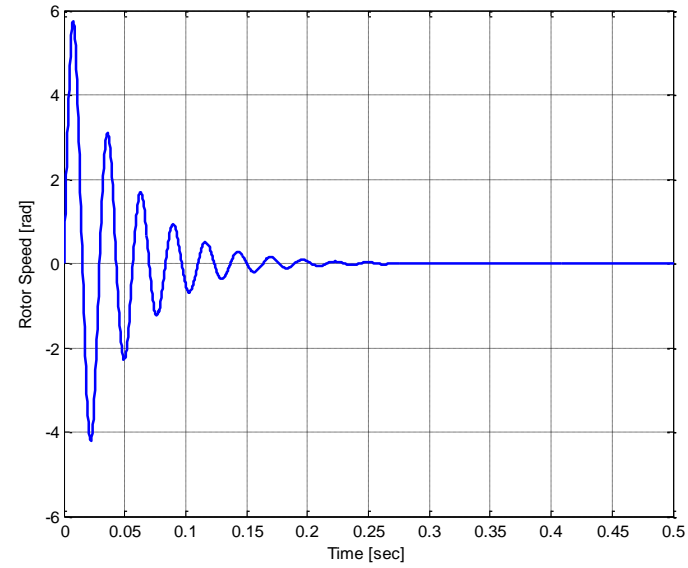

(b) Rotor speed

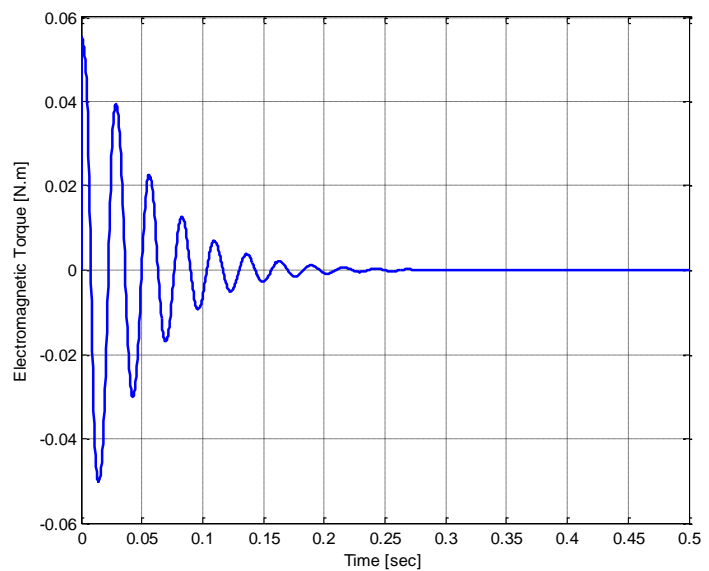

(c) Electromagnetic torque

Fig. 11 Full-step motor performance

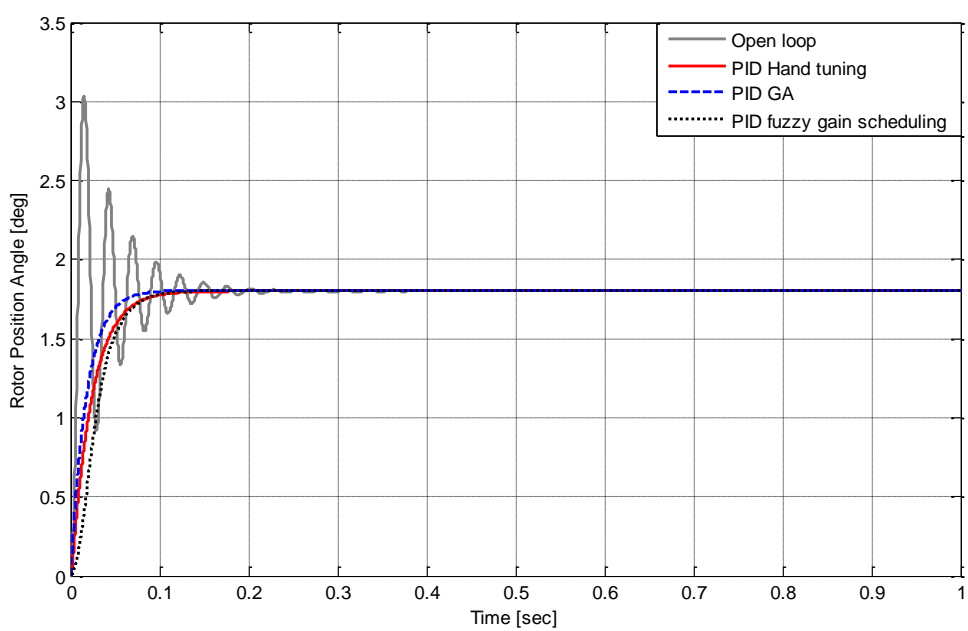

Fig. 12 Comparison between PID controllers with different tuning methods 
The motor performance using different fuzzy controller is compared. It is clear from figure (13) that, the best performance is obtained from fuzzy PID-like controller. The different types eliminate the oscillation around final position, overshoot, and the steady state error. The least rise time and settling time obtained from fuzzy PID-like controller.

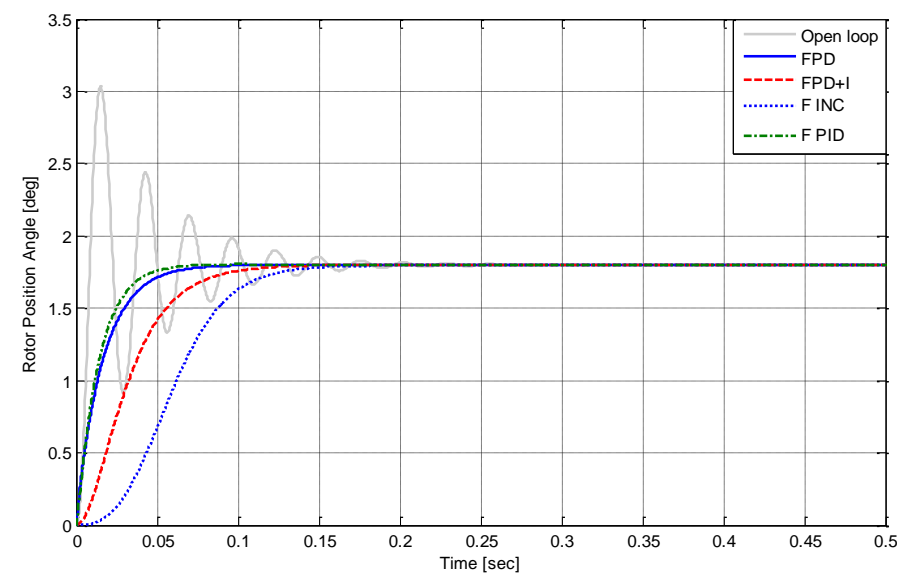

Fig. 13 Comparison between different Fuzzy controllers

Finally, the motor performance using PID with GA and fuzzy PID-like controller is compared. It is clear from figure (14) that, the fuzzy PID-like controller produces better performance.

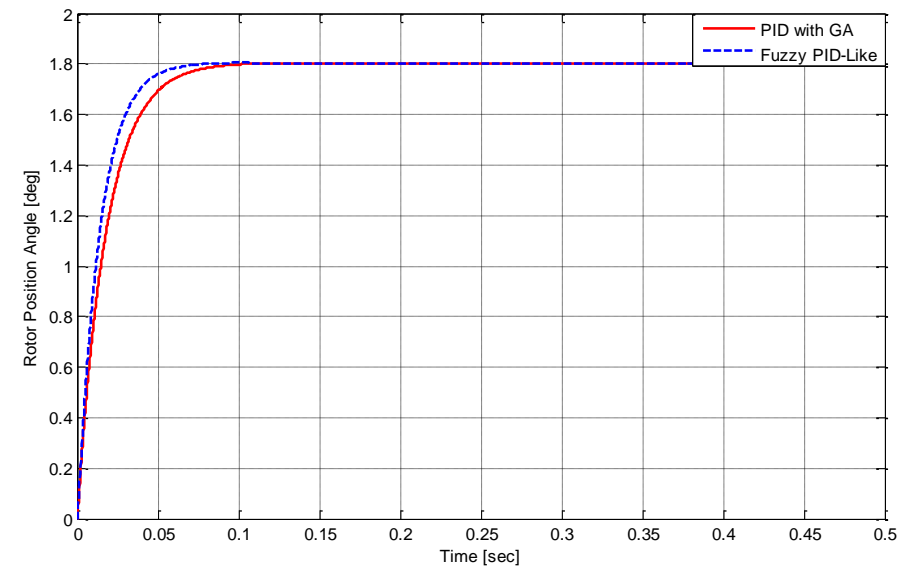

Fig. 14. Comparison between PID with GA and Fuzzy PID-Like Controller

The model with fuzzy PID-like controller is tested to verify the controller capability to follow a reference position, and the results are shown in figure (15). 


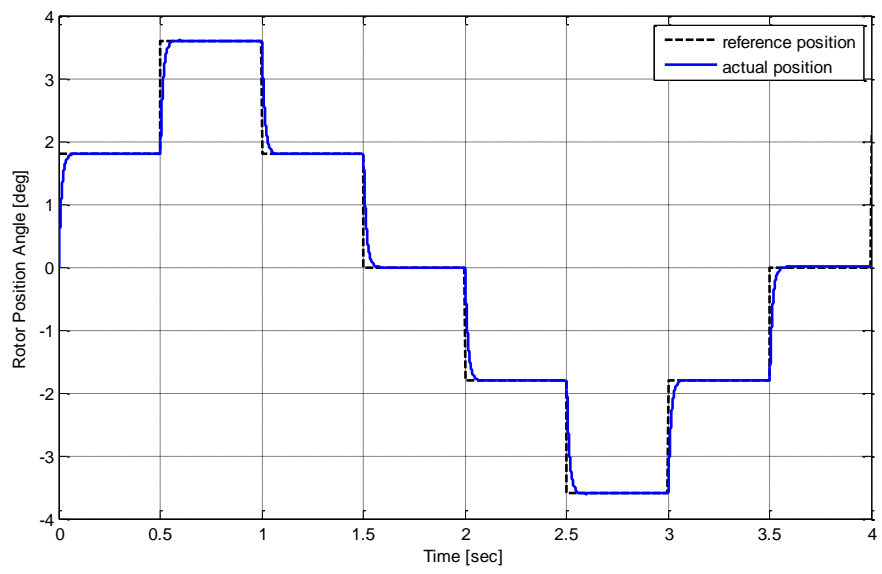

Fig. 15. Motor performance with fuzzy PID-like controller following position trajectory

\section{Conclusion}

Different linear fuzzy controller algorithms for closed-loop control of hybrid stepper motors have been discussed. The numerical simulations by a PC-based controller show that, the fuzzy PID-like controller produces better performance than the other linear fuzzy controllers.

In addition, the genetic algorithm is discussed as a tool for tuning the PID controller gains. Also, the fuzzy logic controller is used to tune the PID controller gains. The numerical simulations by a PC-based controller show that, the PID controller tuned by genetic algorithm produces better performance than that tuned by fuzzy controller.

The comparison between PID controllers tuned by genetic algorithm and fuzzy PID-like controller shows that, the fuzzy PID-like controller produces better performance.

Finally, the fuzzy PID-like controller algorithm for closed-loop control of hybrid stepper motor is tested to prove the capability of the controller.

\section{References}

[1] Zhaojin Wen, Weihai Chen, Zhiyue Xu, and Jianhua Wang, "Analysis of Two-Phase Stepper Motor Driver Based on FPGA", "IEEE International Conference on Industrial Informatics", Pages: 821-826, August 2006.

[2] W. D. Chen, K. L.Yung, and K.W. Cheng, "A Learning Scheme for Low-Speed Precision Tracking Control of Hybrid Stepping Motors", "IEEE/ASME Transactions on Mechatronics", Vol. 11, Issue 3, June 2006.

[3] A. Bellini, C. Concari, G. Franceschini, and A. Toscani, "Mixed mode PWM for high performance stepping motors", "30th Annual Conference of IEEE Industrial Electronics Society", IECON 2004, Vol. 2, Pages: 1212-1217, November 2004.

[4] Ja. Alvarez-Gallegos, E. Alvarez-Sanchez, and R. Castro Linares, "Experimental setup for sensorless rotor position control of a permanent magnet stepper motor", "9th IEEE International Power Electronics Congress", CIEP 2004, Pages: 123-127, October 2004.

[5] M. Zribi and J. Chiasson, "Position control of PM stepper motor by exact linearization","IEEE Transactions on Automatic Control", Vol. 36, Issue 5, May 1991. 
[6] K. R. Rajagopal, M. Krishnaswamy, Bhim Singh, and B. P. Singh "An Improved HighResolution Hybrid Stepper Motor for Solar-Array Drive of Indian Remote-Sensing Satellite" "IEEE Transactions on Industry Applications", Vol. 33, No. 4, July/August 1997.

[7] K.R. Rajagopal, N. Kannan, B. Singh, and B. P. Singh, "An Optimized Module-type Hybrid Stepper Motor for Spacecraft Solar Array Drive", "International Conference on Power Electronics and drive Systems", Vol. 1, Pages: 462-468, May 1997.

[8] A. Selk Ghafari and A. Alasty, "Design and Real-Time Experimental Implementation of Gain Scheduling PID Fuzzy Controller for Hybrid Stepper Motor in Micro-Step Operation", "IEEE International Conference on Mechatronics", Pages: 421-426, June 2004.

[9] J. Persson and Y. Perriard, "Steady state Kalman filtering for sensorless control of hybrid stepper motors", "IEEE International Electric Machines and Drives Conference", IEMDC'03, Vol. 2, Pages: 1174-1177, June 2003.

[10] F. Betin, D. Pinchon, and G. A. Capolino, "Fuzzy Logic Applied to Speed Control of a Stepping Motor Drive", "IEEE Transactions on Industrial Electronics", Vol. 47, Issue 3, June 2000.

[11] Kevin M. Passino and Stephen Yurkovich, "Fuzzy Control", Addison Wesley Longman, California, 1998, ISBN 0-201-18074-X.

[12] Jan Jantzen, "Foundations of fuzzy Control", John Wiley, England, 2007, ISBN 978-0470-02963-3.

[13] Hamdy Abd El-Halim Mohammad, "ANALYSIS AND POSITION CONTROL OF STEPPER MOTOR USING ARTIFICIAL INTELLEGENCE”, PhD thesis, Al-Azhar University, 2006.

[14] Werner Leonhard, "Control of Electric Drives", Springer, 2001.

[15] Yasser Said Mohmoud, "Modern Control Strategies of Electric Machines", Master of Science, MTC, Cairo, 2009.

[16] Amr Ahmed Sarhan, "Design Analysis and Simulation of Satellite Solar Cell Tracking System”, Master of Science, MTC, Cairo, 2011. 